\title{
Geometry determination of tetrasubstituted stilbenes by proton NMR spectroscopy
}

\author{
Viviana S. Fluxá, Titus A. Jenny and Christian G. Bochet* \\ Department of Chemistry, University of Fribourg, 9 Chemin du Musée, CH-1700 Fribourg, Switzerland
}

\begin{abstract}
A simple spectroscopic method was applied to determine the geometry of tetrasubstituted alkenes. The observation of the ${ }^{5} J$ coupling constants in proton NMR spectra on the ${ }^{13} \mathrm{C}$ satellite signals could confirm the previous misassignment of 2,3-diphenylbutene. Hence, the $(E)$-isomer showed a $1.5 \mathrm{~Hz}$ coupling constant, whereas the $(Z)$ isomer showed a $1.1 \mathrm{~Hz}$ coupling constant. Based on this new assignment and a stereospecific preparation, we also propose a revision concerning the NMR data of 2,3-diphenyl-2,3-butanediol.
\end{abstract}

\section{Introduction}

The geometry of 1,2-disubstituted alkenes is routinely determined by proton NMR spectroscopy, through the vicinal coupling constant ${ }^{3} \mathrm{~J}$. For tetrasubstituted alkenes, the observation of NOE effects or the coupling between more distant protons is required, e.g. the ${ }^{5} J$ constant (scheme 1 ).

Scheme 1 . Geometry determination of alkenes by ${ }^{1} \mathrm{H}-\mathrm{NMR}$.
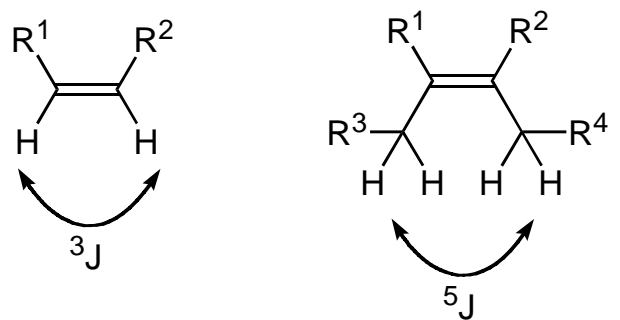

Non-spectroscopic methods, such as chemical derivatization are often tedious, and X-ray quality crystals are not always available.

In the specific case of symmetrical tetrasubstituted alkenes, however, the substituents are related by either a $C_{2}$-axis for the $(E)$-isomer or a plane for the $(Z)$-isomer. Hence, the isochronism between the coupling partners precludes a direct observation of both NOE effects and coupling constants. Special NMR techniques, such as carbon-edited NOESY sequences have been developed for this case, but tested so for only on polyaromatic hydrocarbons. ${ }^{1}$ We report here a quick and simple method to determine the geometry around the double bond in tetrasubstituted stilbene derivatives, and confirm the misassignment of the alkene geometry in the 2,3-diphenyl-2-butene previously published.

\section{Results and discussion}

doi:10.1016/j.tetlet.2005.04.001 
In the course of a structure-activity study of Tamoxifen analogues, we had to prepare both 2,3-diphenyl-2-butene stereoisomers, and ascertain unambiguously their stereochemistry. We chose the simple synthetic sequence described in the scheme 2 .

The addition of methylmagnesium bromide to benzil gave a 90:10 mixture of erythro (meso) and threo (dl) 2,3-diphenyl-2,3butanediol, which was then converted into the desired olefins by an Eastwood deoxygenation. ${ }^{2-4}$ A 94:6 mixture of two olefin isomers was obtained. The near perfect match between the isomer ratios of diols and olefins, together with the known reaction mechanism, confirmed the stereospecificity of the reductive elimination.

Scheme 2. Simple access to tetrasubstituted stilbenes<smiles>O=C(C(=O)c1ccccc1)c1ccccc1</smiles>

1

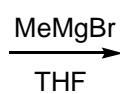

$\mathrm{THF}$<smiles>[R]C([R])(c1ccccc1)[C@@](C)(O)c1ccccc1</smiles>

2a: $\mathrm{R}^{1}=\mathrm{Me}, \mathrm{R}^{2}=\mathrm{OH}$ 2b: $\mathrm{R}^{1}=\mathrm{OH}, \mathrm{R}^{2}=\mathrm{Me}$<smiles>COC(C)C(C)C</smiles><smiles>CC(=C(C)c1ccccc1)c1ccccc1</smiles>

$3 a$<smiles>CC(=C(C)c1ccccc1)c1ccccc1</smiles>

3b

Based on comparison of the ${ }^{1} \mathrm{H}$ - and ${ }^{13} \mathrm{C}$-NMR chemical shifts of the methyl groups with literature values, we initially assigned 3a as the $(Z)$-isomer (1.89 ppm and $25.1 \mathrm{ppm}, \mathrm{H}_{\text {arom }}$ at 7.2-7.4 ppm)) and $3 \mathbf{b}$ as the $(E)$-isomer $(2.19 \mathrm{ppm}$ and 21.4 ppm, $\mathrm{H}_{\text {arom }}$ at 6.9-7.1 ppm). ${ }^{5}$ However, simple qualitative inspection of the structures would predict the opposite assignment. Indeed, the aromatic protons in 3a should have usual chemical shifts (around $7.3 \mathrm{ppm}$ ), whereas $3 \mathbf{b}$ should show a significant shielding, especially for the ortho protons, by the influence of the nearby aromatic ring. ${ }^{6}$ MM2 molecular modelling confirmed this prediction, showing a skewed conformation between the two rings (scheme 3 ).

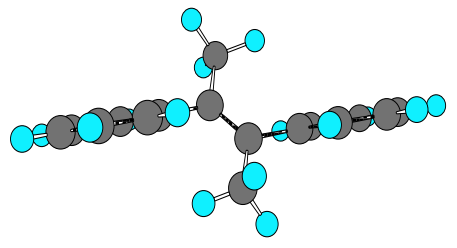

3a

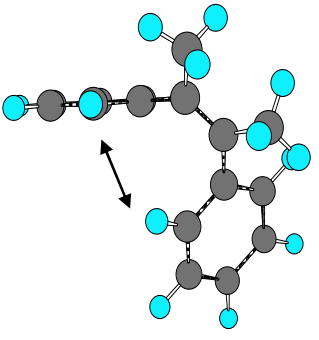

3b

$\leftrightarrow$ Shielding interaction 
Moreover, NMR data in a different solvent also showed the reversed assignement. ${ }^{4}$ Finally, the addition of an excess of a Grignard reagent to benzil is known to give preferentially an erythro stereochemistry. ${ }^{7}$ Since the deoxygenation is stereospecific, the major erythro diasteroisomer $\mathbf{2 b}$ should hence lead to a (Z)-alkene. These discrepancies prompted us to investigate more closely the NMR data.

We took advantage of the well-resolved and intense methyl signals to avoid the tedious synthesis of isotopically enriched compounds. Hence, we turned our attention to the naturally occurring carbon isotope, and observed the ${ }^{13} \mathrm{C}$-satellite signals in the ${ }^{1} \mathrm{H}-\mathrm{NMR}$ spectrum. The isomer 3a revealed quartet sidebands with a ${ }^{5} \mathrm{~J}$ coupling constant of $1.5 \mathrm{~Hz}$ for the $2.01 \mathrm{ppm}$ signal, whereas $\mathbf{3 b}$ showed a coupling constant of $1.1 \mathrm{~Hz}$ on the multiplet satellite of the 2.32 ppm peak (scheme 4). These values are in total agreement with data measured for 2-butenes. ${ }^{8}$ Thus we conclude that $\mathbf{3 a}$ is the (E)-isomer and $3 \mathbf{b}$ is the (Z)isomer. This confirms that the literature values are erroneous. The same conclusion was also found by Andersson on the basis of chemical derivatization and X-ray diffraction analysis. ${ }^{9}$ Since the reductive elimination is stereospecific, ${ }^{2,4}$ we can also conclude that the threo isomer is the diol $\mathbf{2 a}$ ( $\delta$ of the methyl group at $1.54 \mathrm{ppm})$ and the erythro is $\mathbf{2 b}(\delta$ of the methyl group at $1.62 \mathrm{ppm})$. The assignment from recent literature is in this case correct, ${ }^{5}$ but older data is contradictory. ${ }^{10,11}$

Scheme 4. Coupling constants of $\mathbf{3} \mathbf{b}^{13} \mathrm{C}$-satellites.

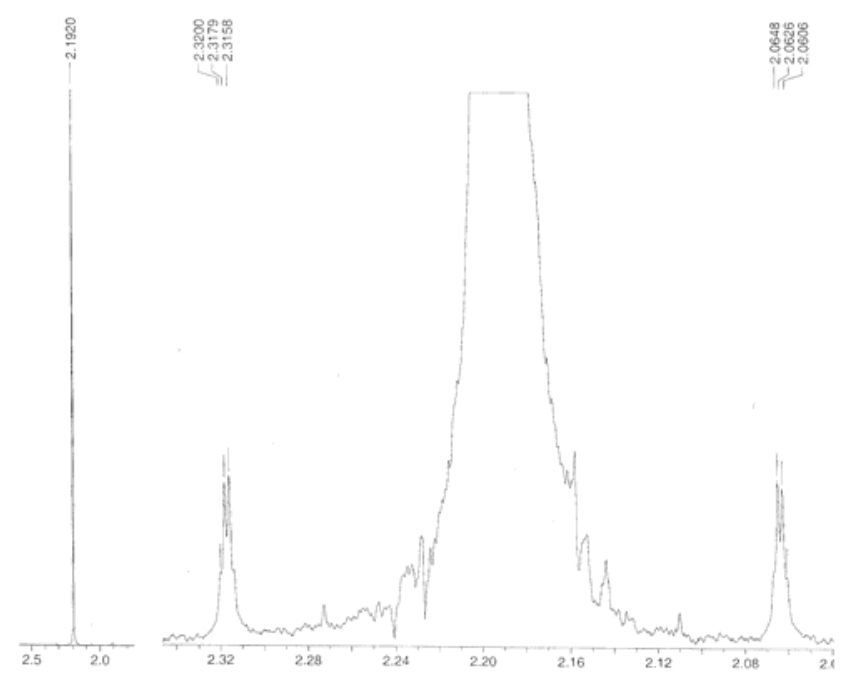

In conclusion, a quick and simple known, but frequently overlooked, spectroscopic method was used to differentiate between $E$ and $Z$ tetrasubstituted olefins. ${ }^{12}$ This technique, however, should be used with confidence only when both isomers are available, since the differences between the coupling constants are small and in the range of substituent effects. This study extends the warning on the assignment of 2,3-diphenylbutene also to 2,3-diphenyl-2,3-butanediol. ${ }^{13}$

\section{Acknowledgments}

We thank Mr. Felix Fehr for his assistance in recording the NMR spectra. The support from the Swiss National Science Foundation (grant 620-066063) is gratefully acknowledged.

\section{References}

1. Hoffman, R. E.; Shenhar, R.; Willner, I.; Bronstein, H. E.; Scott, L. E.; Rajca, A.; Rabinovitz, M. Magn. Reson. Chem. 2000, 38, 311314.

2. Crank, G.; Eastwood, F. W. Aust. J. Chem. 1964, 17, 1392-1398. 
3. Block, E. Org. React. 1984, 30, 478-491.

4. Hiyama, T.; Nozaki, H. Bull. Chem. Soc. Japan 1973, 46, 2248-2249.

5. Szymoniak, J.; Besançon, J.; Moïse, C. Tetrahedron 1992, 19, 3867-3876.

6. Günther, H. NMR-Spektoscopie, $2^{\text {nd }}$ Ed., Georg Thieme, Stuttgart 1983.

7. Clausen, C.; Wartchow, R.; Butenschön, H. Eur. J. Org. Chem. 2001, 93-113.

8. Barfield, M.; Sternhell, S. J. Am. Chem. Soc. 1972, 94, 1905-1913.

9. Andersson, P. Tetrahedron Lett. 1994,35, 2609-2610.

10. Maruyama, K.; Katagiri, T. J. Am. Chem. Soc. 1986, 108, 6263-6279.

11. The melting points quoted for the meso- and the (-)-isomers have to be considered as correct, since they are confirmed by zero and negative optical rotation data: Cram, D.; Kopecky, K. R. J. Am. Chem. Soc. 1959, 81, 2748-2755.

12. Final NMR data (Bruker Avance 500, in $\mathrm{CDCl}_{3}$ ) for 3a: ${ }^{1} \mathrm{H}: 1.89(6 \mathrm{H}),{ }^{13} \mathrm{C}: 25.1 .3 \mathbf{b}:{ }^{1} \mathrm{H}: 2.19(6 \mathrm{H}),{ }^{13} \mathrm{C}: 21.4$.

13. Final NMR data (Bruker Avance 500, in $\mathrm{CDCl}_{3}$ ) for 2a: ${ }^{1} \mathrm{H}: 1.54(6 \mathrm{H}) .2 \mathrm{~b}:{ }^{1} \mathrm{H}$ : $1.62(6 \mathrm{H}),{ }^{13} \mathrm{C}: 143.78,127.27,126.90,126.88,78.57$, 25.11. 